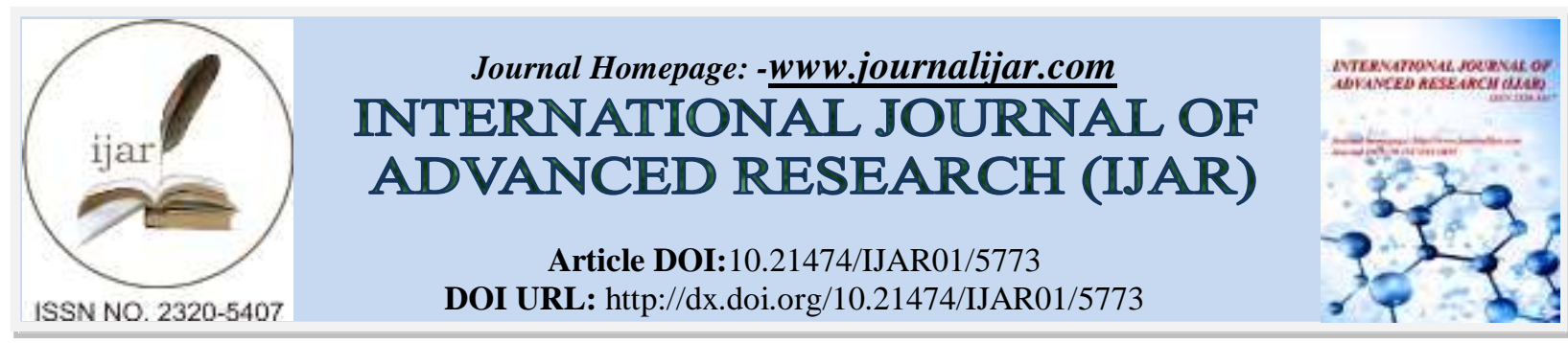

RESEARCH ARTICLE

\title{
A COMPARATIVE EVALUATION OF GINGIVAL ZENITH POSITION AND GINGIVAL ZENITH LINE IN PRE AND POST ORTHODONTIC TREATMENT.
}

\section{Dr. Savita AM ${ }^{1}$, Dr. Prerana GK ${ }^{2}$, Dr. Pallavi Nanaiah ${ }^{3}$ and Dr. Hemanth $\mathrm{M}^{4}$.}

1. HOD and Professor, Department of Periodontics, Dayananda sagar college of dental sciences, Bangalore.

2. PG student, Department of Periodontics, Dayananda sagar college of dental sciences, Bangalore.

3. Senior Lecturer, Department of Periodontics, Dayananda sagar college of dental sciences, Bangalore.

4. HOD and Professor, Department of Orthodontics, Dayananda sagar college of dental sciences, Bangalore.

\section{Manuscript Info}

Manuscript History

Received: 04 September 2017

Final Accepted: 06 October 2017

Published: November 2017

\section{Abstract}

Copy Right, IJAR, 2017,. All rights reserved.

\section{Introduction:-}

An important component of a beautiful smile is esthetics. Gingival health is among the first fundamental esthetic objectives during treatment planning. ${ }^{[1]}$ The ideal gingival architecture consists of knife-edged gingival margin and cone-shaped interdental papilla firmly adapted to the teeth. The beauty of a smile due to altered gingival contours is influenced by the gingival zenith.

The most apical aspect of the free gingival margin is known to be as gingival zenith. ${ }^{[2,3]}$ This was described as having a specific spatial orientation in the apico-coronal and mesio-distal directions. ${ }^{[4]}$ To establish the proper gingival contour two clinical parameters were used as esthetic guidelines such as (1) Gingival zenith position (GZP) i.e., the distance from the highest gingival margin position to the vertical bisected midline (VBM) in a medial-lateral direction. ${ }^{[1]}$ The position of the zenith will help to create the desired axial inclination of the tooth by changing the line angle position of the long axis of the tooth. ${ }^{[2]}(2)$ Gingival zenith line (GZL) i.e., the line joining the tangents of the gingival zeniths of the central incisor and canine and relatively measured for lateral incisor in an apical-coronal direction. ${ }^{[1]}$ The zenith of the central incisor and canine are found to be at distal third [central incisor is more distally placed than canine] and the lateral incisor usually coincides along the long axis of the tooth ${ }^{[1,2]}$ and rarely found at the distal third. Ideal gingival zenith is a prerequisite for achieving long term prognosis for most of the esthetic dental procedures like crown lengthening, plastic gingival surgeries etc. In case of orthodontic treatment procedures, gingival zenith holds a considerable position in determining the post orthodontic treatment success. However, to the best of our knowledge there are limited literatures available regarding the attainment of ideal gingival zenith postorthodontically.

Hence, the purpose of this study was to assess the clinical parameters i.e., GZP and GZL and also to compare in Angle's class I occlusion, pre and post orthodontic treatment casts of the maxillary anterior dentition. 


\section{Materials and methods:-}

The study was conducted in Dayananda sagar college of Dental sciences, Bangalore, India. A total of 15 individuals comprising of 180 sites and divided into three groups with an age group range of 18 to 23 years (mean age 20.6 years) were enrolled in the study.

\section{Inclusion criteria:-}

1. Group 1(control - 5 subjects): Angle's class I occlusion without any dental deformity.

2. Group 2 (pre-orthodontic treatment -5 subjects): Angle's class I malocclusion of the maxillary anterior dentition.

3. Group 3 (post-orthodontic treatment -5 subjects): Correction of Angle's class I malocclusion of the maxillary anterior dentition.

\section{Exclusion criteria:-}

1. Excessive incisal attrition.

2. Gingival recession.

3. Gingival enlargement.

4. History of restorative, periodontal and surgical treatment.

Alginate impressions of maxillary arch were made using stock trays and casts were obtained for Group 1 (figure 1). The pre and post orthodontic treatment casts were obtained from the previous records (secondary data) of the patients treated in the Department of Orthodontics, Dayananda sagar College of dental sciences, Bangalore, India for Group 2 and 3 respectively (figure $2 \& 3$ ). A calibrated digital caliper was used to measure the clinical parameters such as GZP and GZL on the maxillary anterior teeth from canine to canine. To evaluate GZP, the tooth width was measured at two reference points i.e., the proximal incisal contact area position (ICAP) and the apical contact area position (ACAP). Each width was divided into half and the center points were marked. Center points were extended to a line toward the gingival aspect of the clinical crown to define the vertical bisected midline (VBM) and then the highest point of the free gingival margin was marked (figure $4 \& 5$ ). The distance of the highest gingival margin position to the VBM was measured on all the maxillary anterior teeth to obtain the GZP in a mesio-distal direction (figure 6). To evaluate GZL, a line joining the tangents of the gingival zenith of the central incisor and canine was drawn. The distance of the contour of the gingival margin for the LI was measured from the gingival line relative to $\mathrm{CI}$ and C to obtain the GZL in an apico-coronal direction (figure 7 and 8). All the data were statistically analyzed by independent sample t-test between group 1 and group 2 and between group 1 and group 3. For the data analysis between group 2 and group 3 paired sample t-test was used. $P$ value $\leq 0.05$ was considered as statistically significant.

\section{Results:-}

Of the total 15 cases, the mean GZP values from upper right canine to left canine (13 to 23) in Group 1 are 0.19 , $0.45,0.81,0.81,0.35,0.22$, in Group 2 are 0.37, 0.58, 0.95, 0.91, 0.56, 0.41, and in Group 3 are 0.15, 0.31, 0.69, $0.71,0.30,0.10$ respectively (Table 1). The mean GZL valuesfor upper right and left lateral incisors(12 and 22) in group 1 are $0.81,0.86$, in group 2 are $0.85,0.87$ and in group 3 are $0.83,0.85$ respectively (Table 2 ).

A total of three groups were formed to assess the GZP values in six teeth and GZL values in upper right and left lateral incisors. There was no statistical significance in GZP values $(\mathrm{p}=0.275)$ between group 1 and group 2 (Table 3). Significant GZP values for upper right canine (13) ( $\mathrm{p}=0.038)$, right lateral incisor (12) $(\mathrm{p}=0.015)$, right central incisor (11) $(\mathrm{p}=0.022)$, left canine (23) $(\mathrm{p}=0.040)$ were found between group 2 and group 3 (Table 3). On comparison between group 1 and group 3 there was no statistical significance in the GZP values ( $\mathrm{p}=0.424)$ (Table 3 ). There was no statistical significance in the GZL values on comparison between group 1 and group 2 ( $\mathrm{p}=0.687$ ), group 2 and group $3(\mathrm{p}=0.720)$ and group 1 and group $3(\mathrm{p}=0.907)$ (Table 4$)$.

\section{Discussion:-}

The physiologic gingival architecture around the two surfaces of the tooth has been described as having a scalloped contour. The aesthetics of the smile is directly related to the position of the gingival zenith. The most apical point of the gingival marginal scallop is known as gingival zenith. ${ }^{[2]}$

Kokich et al (1999) $)^{[5]}$ in a study suggested that if the gingival contour asymmetry is located close to the midline, it will be identified as unesthetic more easily. He also added that esthetics will be compromised whenever the height 
of the gingival margin of the lateral incisor is positioned more than $2 \mathrm{~mm}$ above the gingival margin of the central incisor and canine.

Rufenacht $(2000)^{[6]}$ described that the gingival zenith position was distally displaced on the central incisor and canine only, whereas for lateral incisor it was corresponding with the vertical bisected midline and the ideal gingival zenith line for class I occlusion of the central incisor and canine are at the same level and the lateral incisor was positioned slightly more coronal.

Goodlin $(2003)^{[7]}$ described that the zenith of the central incisor should be at the distal third, the lateral incisor in the middle and the cuspid can range from anterior third to the distal third. The study also described that the gingival zenith position will help to create the desired axial inclination of the tooth by changing the line angle position of the long axis of the tooth.

The clinical parameters such as the gingival zenith position and the gingival zenith line significantly influence the aesthetic appearance of a smile and also helps to facilitate as a reference point during periodontal esthetic procedures. The gingival zenith is important in planning the treatment for the correction of rotated anterior teeth and also to improve the dental implant esthetics which will indeed control the factors such as depth of the dental implant placement, response of the buccal bone and mucosa to the implant procedure and prosthodontic management of the gingival zenith architecture. ${ }^{[8]}$

The gingival zenith position and gingival zenith line have an important role in the orthodontic treatment procedures for determining the post orthodontic treatment success. As described by Rufenacht (2000) our study having a sample of Angle's Class I malocclusion showed that the gingival zenith of post orthodontic treatment group was same as that of angle's class I occlusion group. Contrary to our study Snigdha Gowd et al (2017) ${ }^{[9]}$ found that there is variation in the location of gingival zenith position in Angle's Class I malocclusion with varying crown inclination. Hence, an attempt was made in this study to evaluate the gingival zenith position and line in both ideal angle's class I occlusion and post orthodontic treatment group. The drawback in our study was the smaller sample size in each group and further studies are needed to evaluate the angle's class I occlusion and post orthodontic treatment groups with a larger sample size.

\section{Conclusion:-}

Our study provided quantitative measurements of GZP and GZL in correspondence to class I malocclusion. This reference points highlights the prime importance of maintaining gingival architecture during and after orthodontic treatment. Hence, these reference points can be used in conjunction with other esthetic parameters during the diagnosis and treatment planning to replicate a natural smile.

\begin{tabular}{|l|l|l|l|}
\hline \multirow{2}{*}{ TOOTH NUMBER } & \multicolumn{3}{|c|}{ MEAN \pm SD } \\
\cline { 2 - 4 } & GROUP I & GROUP II & GROUP III \\
\hline 11 & $0.81 \pm 0.24$ & $0.95 \pm 0.22$ & $0.69 \pm 0.21$ \\
\hline 12 & $0.45 \pm 0.20$ & $0.58 \pm 0.20$ & $0.31 \pm 0.09$ \\
\hline 13 & $0.19 \pm 0.18$ & $0.37 \pm 0.18$ & $0.15 \pm 0.17$ \\
\hline 21 & $0.81 \pm 0.28$ & $0.91 \pm 0.21$ & $0.71 \pm 0.17$ \\
\hline 22 & $0.35 \pm 0.11$ & $0.56 \pm 0.25$ & $0.30 \pm 0.07$ \\
\hline 23 & $0.22 \pm 0.11$ & $0.41 \pm 0.16$ & $0.10 \pm 0.14$ \\
\hline
\end{tabular}

Table 1: Mean and standard deviation of gingival zenith position (GZP) of all the three groups

\begin{tabular}{|l|c|c|c|}
\hline \multirow{2}{*}{ TOOTH NUMBER } & \multicolumn{3}{|c|}{ MEAN \pm SD } \\
\cline { 2 - 4 } & GROUP I & GROUP II & GROUP III \\
\hline 12 & $0.81 \pm 0.16$ & $0.85 \pm 0.27$ & $0.83 \pm 0.23$ \\
\hline 22 & $0.86 \pm 0.14$ & $0.87 \pm 0.27$ & $0.85 \pm 0.23$ \\
\hline
\end{tabular}

Table 2: Mean and standard deviation of gingival zenith line (GZL) of all the three groups

\begin{tabular}{|l|l|l|l|l|}
\hline TOOTH NUMBER & $\begin{array}{l}\text { INDEPENDENT } \\
\text { SAMPLE 't' } \\
\text { (GROUP I AND II) }\end{array}$ & TEST & $\begin{array}{l}\text { PAIRED SAMPLE 't' } \\
\text { TEST (GROUP II AND } \\
\text { III) }\end{array}$ & $\begin{array}{l}\text { INDEPENDENT } \\
\text { SAMPLE 't' TEST } \\
\text { (GROUP I AND III) }\end{array}$ \\
\hline
\end{tabular}




\begin{tabular}{|l|l|l|l|l|l|l|}
\hline & 't' value & 'p' value & 't' value & 'p' value & 't' value & 'p' value \\
\hline 11 & -0.957 & 0.367 & 3.647 & $\mathbf{0 . 0 2 2}^{*}$ & 0.773 & 0.462 \\
\hline 12 & -0.961 & 0.365 & 4.121 & $\mathbf{0 . 0 1 5}^{*}$ & 1.437 & 0.189 \\
\hline 13 & -1.512 & 0.169 & 3.054 & $\mathbf{0 . 0 3 8}^{*}$ & 0.349 & 0.736 \\
\hline 21 & -0.610 & 0.559 & 1.876 & 0.134 & 0.681 & 0.515 \\
\hline 22 & -1.668 & 0.134 & 2.531 & 0.065 & 0.771 & 0.463 \\
\hline 23 & -2.180 & 0.061 & 2.987 & $\mathbf{0 . 0 4 0}$ & 1.461 & 0.182 \\
\hline & $\begin{array}{l}\text { Mean- } \\
\text { (j).275 }\end{array}$ & & & $\begin{array}{l}\text { Mean- } \\
\text { 0.424 }\end{array}$ \\
\hline
\end{tabular}

Table 3:-Comparison of gingival zenith position (GZP) in all the three groups

\begin{tabular}{|c|c|c|c|c|c|c|}
\hline \multirow[t]{2}{*}{ TOOTH NUMBER } & \multicolumn{2}{|c|}{$\begin{array}{l}\text { INDEPENDENT } \\
\text { SAMPLE ' } \mathrm{t} \text { ' } \\
\text { (GROUP I AND II) }\end{array}$} & \multicolumn{2}{|c|}{$\begin{array}{l}\text { PAIRED SAMPLE 't' } \\
\text { TEST (GROUP II AND } \\
\text { III) }\end{array}$} & \multicolumn{2}{|c|}{$\begin{array}{l}\text { INDEPENDENT } \\
\text { SAMPLE ' } \mathrm{t} \text { ' TEST } \\
\text { (GROUP I AND III) }\end{array}$} \\
\hline & 't' value & 'p' value & 't' value & 'p' value & 't' value & 'p' value \\
\hline 12 & 0.252 & 0.853 & 0.221 & 0.836 & -0.125 & 0.903 \\
\hline 22 & 0.436 & 0.521 & 0.562 & 0.604 & 0.114 & 0.912 \\
\hline & & $\begin{array}{l}\text { Mean- } \\
\text { 0.687 }\end{array}$ & & $\begin{array}{l}\text { Mean- } \\
\text { 0.720 }\end{array}$ & & $\begin{array}{l}\text { Mean- } \\
0.907\end{array}$ \\
\hline
\end{tabular}

Table 4:-Comparison of gingival zenith line (GZL) in all the three groups

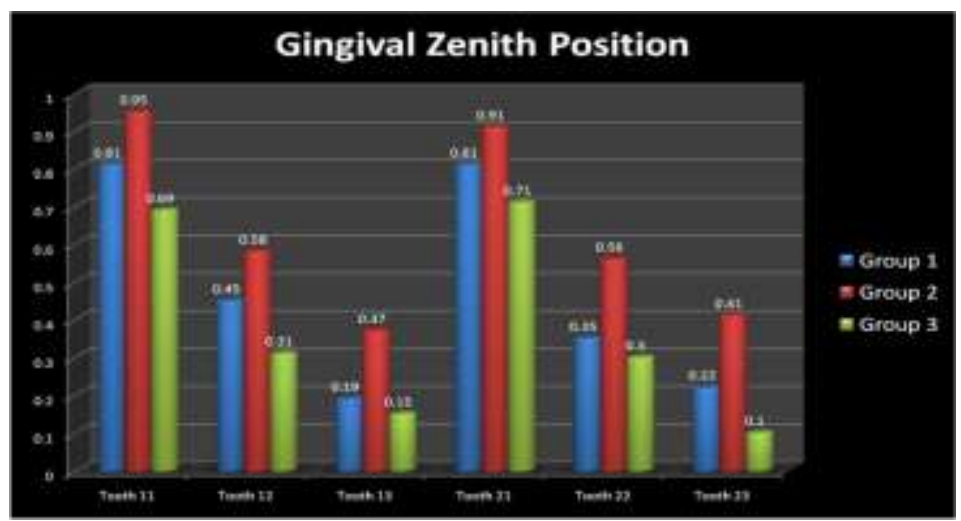

Gingival zenith position (GZP).

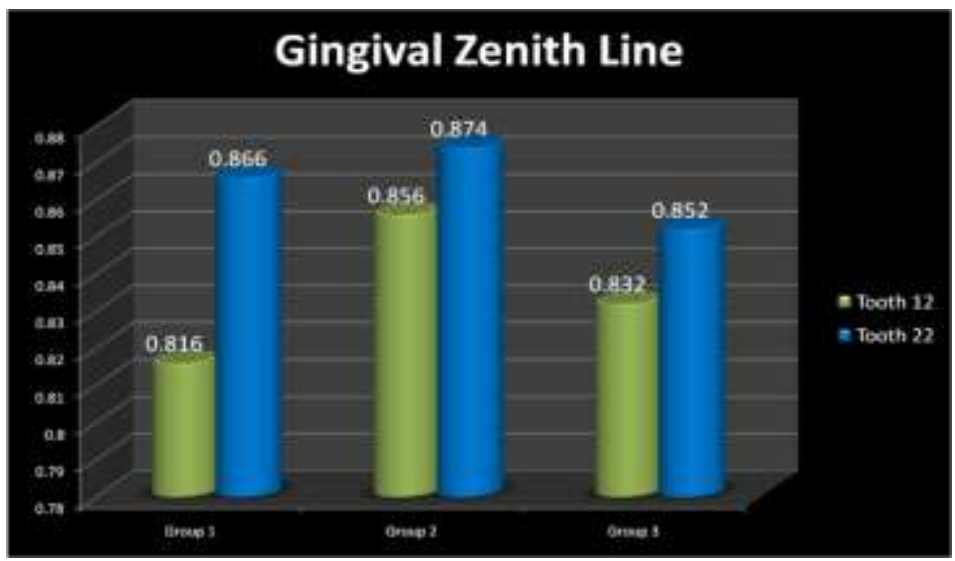

Gingival zenith line (GZL) 


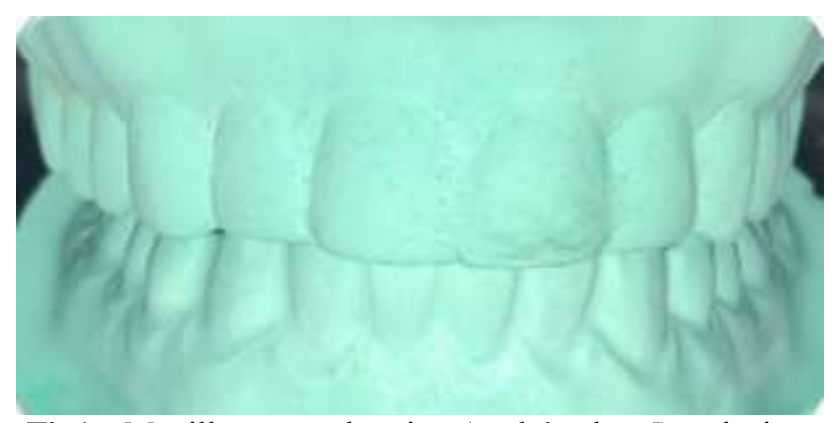

Fig1:- Maxillary cast showing Angle's class I occlusion.

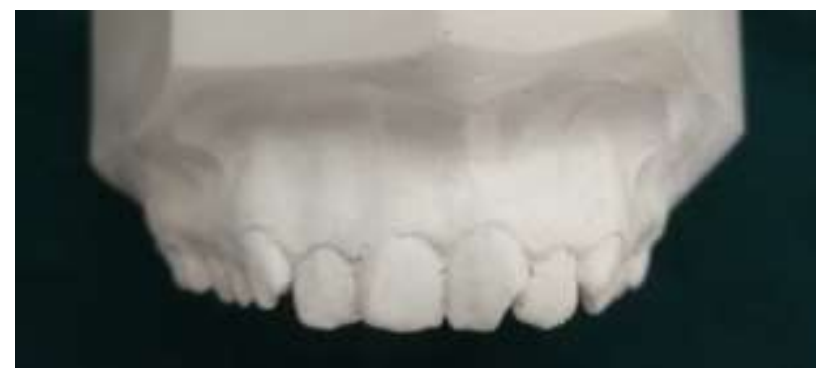

Fig 2:- Maxillary pre-treatment cast showing Angle's class I malocclusion.

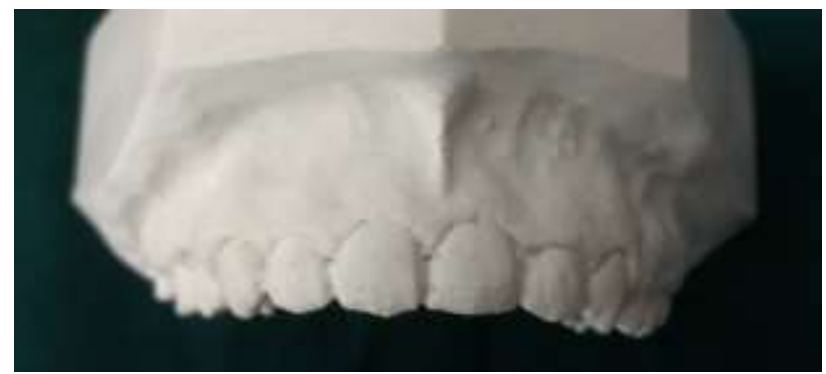

Fig 3:- Maxillary post-treatment cast showing Angle's class I malocclusion

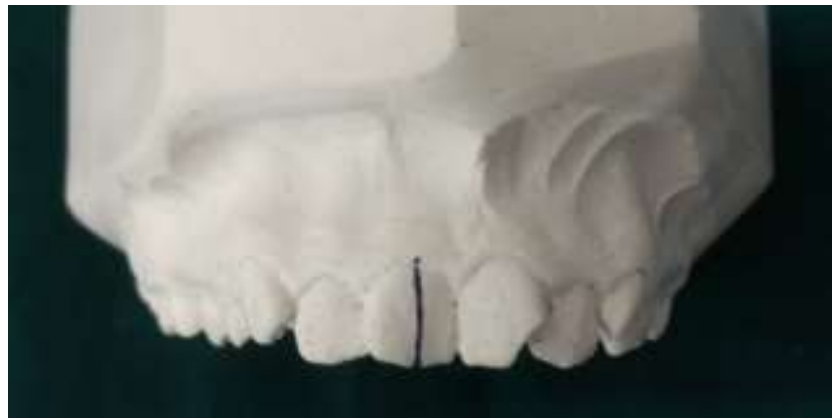

Fig 4:- Maxillary pre-treatment cast showing Angle's class I malocclusion indicating vertical bisected midline.

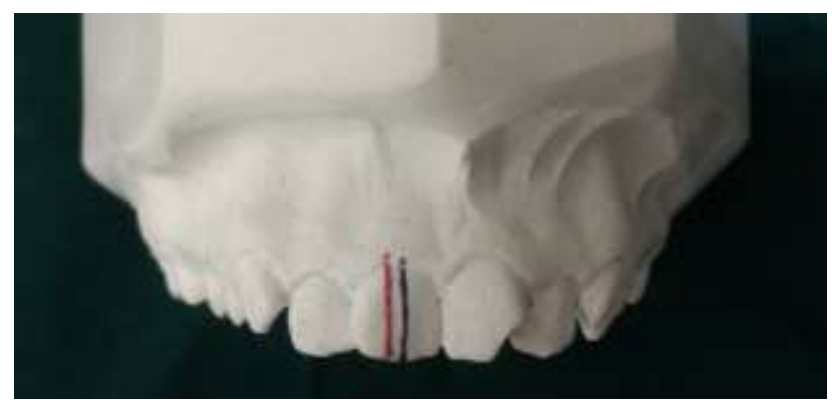


Fig 5:- Maxillary pre-treatment cast showing Angle's class I malocclusion indicating highest gingival margin position.

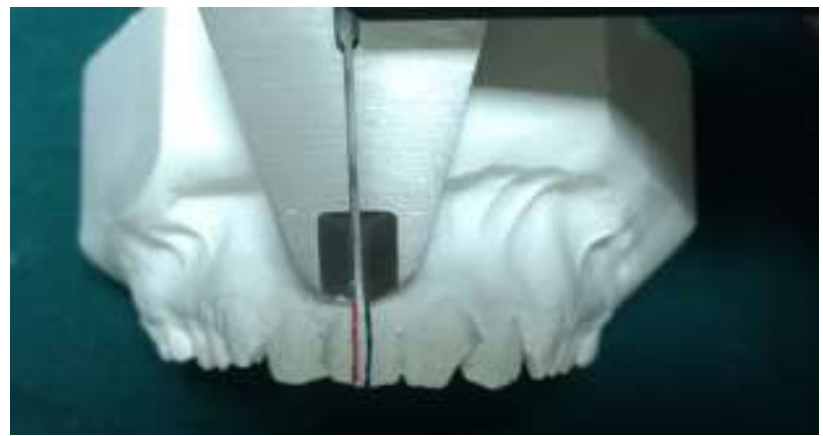

Fig 6:- Maxillary pre-treatment cast showing Angle's class I malocclusion indicating gingival zenith position.

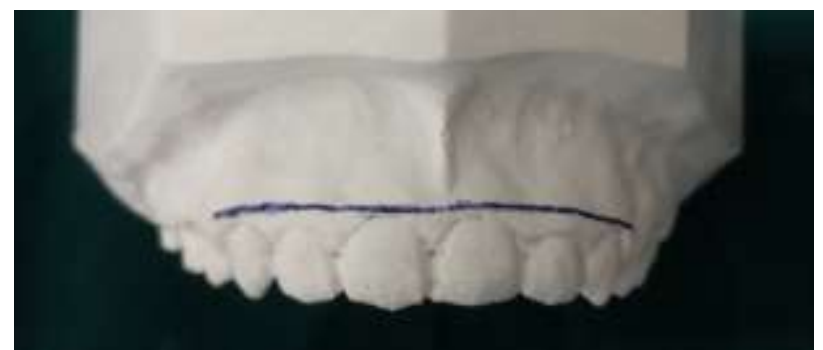

Fig 7:- Maxillary post-treatment cast indicating highest gingival margins.

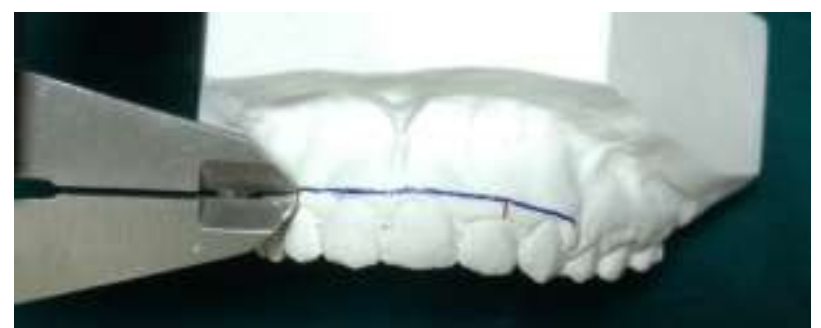

Fig 8:- Maxillary post-treatment cast indicating gingival zenith line.

\section{References:-}

1. Chu SJ et al (2009): Gingival Zenith Positions and Levels of the Maxillary Anterior Dentition. J EsthetRestor Dent., 21:113-121.

2. Pawar B et al (2011): Gingival zenith and its role in redefining esthetics: A clinical study. J Indian SocPeriodontol., 15:135-8.

3. Charruel S et al (2008): Gingival Contour Assessment: Clinical Parameters Useful for Esthetic Diagnosis and Treatment. J Periodontol., 79:795-801.

4. Mattos CML et al (2008): A Quantitative Evaluation of the Spatial Displacement of the Gingival Zenith in the Maxillary Anterior Dentition. J Periodontol., 79:1880-85.

5. Kokich VO Jr et al (1999): Comparing the perception of dentists and lay people to altered dental esthetics. J Esthet Dent., 11(6):311-24.

6. Rufenacht CR (2000): Principles of esthetic integration. Chicago (IL): Quintessence.

7. Goodlin R (2003): Gingival aesthetics: a critical factor in smile design. Oral Health and Dental Practice., 93(4):10-27.

8. Shah D et al (2014): Relative position of gingival zenith in maxillary anterior teeth- a clinical appraisal. International J. of Healthcare and Biomedical Research., 3:77-81.

9. Gowd S et al (2017): Gingival zenith positions and levels of maxillary anterior dentition in cases of bimaxillary protrusion: A morphometric analysis. The Journal of Contemporary Dental Practice., 18(8):700-704. 